\title{
CORRELAÇÃO ENTRE OS RESULTADOS DE PROTEÍNA C-REATIVA E VELOCIDADE DE HEMOSSEDIMENTAÇÃO
}

\section{CORRELATION BETWEEN RESULTS OF C-REACTIVE PROTEIN AND ERYTHROCYTE SEDIMENTATION RATE}

\author{
Jéssica Valadas ${ }^{\mathrm{a}^{*}}$, Vitória Foigt $^{\mathrm{b}^{*}}$, Wagner de Aguiar Raupp $\mathrm{c}^{\mathrm{c}^{*}}$, Thiago Aley Brites de Freitas, \\ Liane Rotta $\mathrm{d}^{\star}$
}

valadasjessica@gmail.comª, vitoriafoigt@hotmail.com ${ }^{\mathrm{b}}$, raupp@feevale.brc, thiagobrites@gmail.com ${ }^{\mathrm{d}}$, lnrotta@ufcspa.edu.br Universidade Federal de Ciências da Saúde de Porto Alegre

Data de Submissão: 19/08/2018

Data de Aceite: 17/01/2019

\section{RESUMO}

A inflamação é uma resposta natural do organismo que ocorre em diversos quadros patológicos, desde os mais simples até os mais graves. Dentre os métodos laboratoriais rotineiros, os mais utilizados para triagem e detecção de processos inflamatórios são a velocidade de hemossedimentação (VHS) e a dosagem da proteína C-reativa (PCR), respectivamente. No entanto, cada vez mais se tem comparado e debatido o valor diagnóstico e prognóstico destes testes. Nesse contexto, o objetivo do trabalho foi comparar e correlacionar os dados de VHS e PCR de pacientes atendidos em laboratório da região metropolitana de Porto Alegre. Os valores obtidos mostraram resultados acima dos indicados pelos valores de referência, havendo correlação entre sexo e idade. Tais dados mostram o perfil geral de uma população aos procedimentos empregados, além de sugerirem os testes mais adequados a serem usados de acordo com as características dos pacientes.

Palavras-chave: Proteína C-reativa; Velocidade de hemossedimentação; Diagnóstico;

\begin{abstract}
Inflammation is a natural response of the body that occurs in various pathological conditions, from the simplest to the most serious. Among routine laboratory methods, the most commonly used for screening and detection of inflammatory processes are erythrocyte sedimentation rate (ESR) and C-reactive protein (CRP) dosage, respectively. However, the diagnostic and prognostic value of these tests has been compared and debated. In this context, the objective of the study was to compare and correlate the CRP and ESR data in the metropolitan area of Porto Alegre. The values obtained showed results above those indicated by the reference values, and there is still a correlation between sex and age with the results. These data showed the general profile of a population to the procedures used, besides suggesting the most appropriate tests to be used according to the characteristics of the patients.
\end{abstract}

Keywords: C-reactive protein, erythrocyte sedimentation rate, diagnosis 


\section{Introdução}

A inflamação é uma resposta evolutiva natural do organismo. Por seu amplo espectro pode estar relacionada desde os quadros mais leves, como infecções virais amenas, até situações de maior gravidade, incluindo lesão tecidual ${ }^{1}$. Em um processo inflamatório agudo ocorre o aumento do fluxo sanguíneo, por meio do qual diversos componentes do sistema imune, especialmente leucócitos, migram para o local de foco da lesão. Macrófagos e mastócitos, também transportados pela corrente sanguínea, são responsáveis por liberar uma cascata de mediadores inflamatórios como quimiocinas e citocinas. Posteriormente, esses mediadores serão os responsáveis pela produção do exsudato, levando ao extravasamento de proteínas e leucócitos para os tecidos ${ }^{1}$.

A ocorrência do processo inflamatório é, muitas vezes, fisiologicamente necessária para a recuperação do organismo. Entretanto, a inflamação em excesso pode desencadear quadros patológicos de maior severidade. Nesse cenário a participação da inflamação tem sido estudada em quadros de stress, diabetes ${ }^{2}$, obesidade ${ }^{3}$, doenças reumatoides ${ }^{4}$, câncer ${ }^{5} \mathrm{e}$, principalmente, aterosclerose e doenças cardiovasculares em geral 6,7 .

Por estar ligada a diversas doenças de alta incidência, a detecção de processos inflamatórios com o uso de marcadores laboraotiais é bastante solicitada ${ }^{8,9}$. Dentre os marcadores laboratoriais para este propósito, bastante utlizados em laboratórios de portes variados, cita-se a dosagem da proteína C-reativa (PCR) e a velocidade de hemossedimentação (VHS).

A proteína C-reativa é produzida no fígado em situação de homeostase. No entanto, durante o processo inflamatório agudo, a interleucina-6 (IL-6) estimula os hepatócitos a produzirem mais desse marcador bioquímico, de forma que a PCR tende a ter um pico facilmente detectável por meio da dosagem no soro ${ }^{10}$. A VHS é um teste usado há mais tempo, quando comparado à dosagem de PCR. O método consiste em medir, após passada 1 hora, a sedimentação do sangue habitualmente coletado em EDTA, ou feito a partir de diluições com citrato de sódio ou soro fisiológico, numa pipeta graduada posicionada verticalmente em temperatura ambiente $\mathrm{e}$ estável ${ }^{11}$. Diferente da PCR, em que se realiza pesquisa direta da molécula na amostra, a VHS permite a detecção indireta de fibrinogênio e outras proteínas responsivas à fase inflamatória aguda no sangue. Durante a inflamação, essas proteínas plasmáticas são liberadas na circulação em maior quantidade, incluindo o fibrinogênio e globulinas. Essas proteínas dificultam a repulsão natural das hemácias diminuindo seu potencial eletronegativo, assim fazendo com que o sangue sedimente mais rápido e permitindo a aferição de um possível processo inflamatório ${ }^{12}$.

Por serem dois métodos bastante acessíveis, práticos e de baixo custo, o uso de PCR e da VHS tem sido comparado por diversos estudos. Com relação ao teste de eleição, existe bastante divergência. Estudos que indicam a proteína C-reativa como mais indicada para a detecção de inflamação afirmam que a molécula é mais específica ${ }^{13}$, enquanto existem dados que apontam para igual efetividade dos dois métodos ${ }^{14}$. Todavia, algo que a maioria das pesquisas anteriormente citadas concorda, é que existe uma importante variação nos resultados esperados para ambos os exames.

Estudos demonstraram a influência que fatores como a idade, sexo, estilo de vida, etnia, histórico médico e até mesmo o local de residência podem ter sobre os resultados laboratoriais ${ }^{15,16}$. Por esse motivo, é recomendado que a avaliação desses marcadores seja adaptada de acordo com a realidade de cada região e a escolha do teste mais adequado para determinada situação. Tendo em vista que o Brasil ainda tem doenças relacionadas a processos inflamatórios como grande preocupação na saúde pública ${ }^{17}$, a abordagem dos testes diagnósticos é de extrema importância para uma possível prevenção de casos mais graves. Nesse contexto, o objetivo deste estudo foi correlacionar os resultados da proteína C-reativa e velocidade de hemossedimentação em pacientes de um hospital na região metropolitana de Porto Alegre. 


\section{Metodologia}

Foi realizado um estudo de abordagem quantitativa e com delineamento transversal utilizando o banco de dados de um hospital na região metropolitana de Porto Alegre.

Como critério de inclusão cita-se a utilização de amostras nas quais haviam sido realizadas a determinação dos níveis séricos de proteína C-reativa associados à velocidade de hemossedimentação e que ambos os testes fossem provenientes da mesma punção venosa periférica. Os dados foram categorizados de acordo com as variáveis: valores de PCR, valores de VHS, sexo e idade. A amostra do estudo foi constituída por 1.321 resultados obtidos entre janeiro de 2015 e janeiro de 2016.

Os resultados para PCR e VHS foram obtidos através de métodos estipulados pelo Procedimento Operacional Padrão (POP) do laboratório da instituição hospitalar, o qual foi estabelecido de acordo com as informações dos fabricantes dos produtos bem como diretrizes nacionais e internacionais.

Para a determinação quantitativa da proteína C-reativa utilizou-se amostras de soro coletadas em tubos com gel separador e ativador de coágulo. A metodologia utilizada foi a imunoturbidimetria, na qual as partículas de látex estabilizadas e sensibilizadas com o anticorpo anti-proteína C-reativa aglutinam, sendo possível medi-las em unidade de absorbância e a intensidade da aglutinação é diretamente proporcional à quantidade de PCR na amostra. As amostras foram processadas em equipamento automatizado BT 3000 Plus (Wiener) devidamente calibrado e submetido procedimentos de controle de qualidade.

A quantificação do VHS foi realizada pelo método Westergren. As amostras foram coletadas em tubo com Citrato de Sódio 3,2\% e analisadas em pipetas plásticas graduadas. A pipeta acoplada ao tubo permaneceu durante 1 hora em posição vertical, em bancada estável e em temperatura de $21 \pm 2^{\circ}$ C. Ao final do tempo estabelecido foi feita a aferição manual da sedimentação das hemácias utilizando o sistema métrico da pipeta, gerando um resultado em milímetros na primeira hora.
Para a análise estatística foi realizada a correlação de Spearman seguida do teste de Mann-Whitney. Também foi calculada a mediana das variáveis. Utilizou-se o software SPSS 18.0 na preparação e análise dos dados coletados.

\section{Resultados}

Conforme indicado pela tabela 1 , os pacientes analisados tiveram leve predominância do sexo feminino, representando 52,7\% das amostras (696 pacientes) em um total de 1321 pacientes. Já do sexo masculino foram 625 amostras e $47,3 \%$ das amostras analisadas. Com relação a idade foi calculada a mediana de 44 anos entre o total de pacientes. Os resultados de VHS e PCR tiveram mediana de 23,0 mm e 11,8 mg/L, respectivamente.

$\mathrm{O}$ teste para correlação de Spearman indicou rô (r) de 0,528 e nível de significância $(\mathrm{p})<0,001$, apontando correlação entre os resultados de VHS e PCR. Por fim, no teste de Mann-Whitney (tabela 2), considerando o sexo feminino e masculino como grupos diferentes, calculou-se a mediana da idade para as mulheres de 45,5 anos e 42 anos para os homens. Os resultados de VHS para mulheres obtiveram mediana de $25 \mathrm{~mm}$ e para os homens de $20 \mathrm{~mm}$.

Para o PCR os resultados de mediana para mulheres foram de $10 \mathrm{mg} / \mathrm{L}$ e $15 \mathrm{mg} / \mathrm{L}$ para homens.

Tabela 1 - Dados gerais da população do estudo

\begin{tabular}{ccc}
\hline Variável & Mediana & {$[\mathrm{q} 1-\mathrm{q} 3]$} \\
\hline Idade & 44,0 & {$[24-65]$} \\
VHS & 23,0 & {$[10-53]$} \\
PCR & 11,8 & {$[4,5-39,3]$} \\
\hline Sexo & $\mathrm{N}$ & $\%$ \\
\hline Feminino & 696 & 52,7 \\
Masculino & 625 & 47,3 \\
Total & 1321 & 100 \\
\hline
\end{tabular}


Tabela 2 - Valores de Proteína C reativa e velocidade de hemossedimentação, de acordo com o sexo

\begin{tabular}{cccccc}
\hline & Feminino & \multicolumn{2}{c}{ Masculino } & \multirow{2}{*}{$\mathrm{p}$} \\
\cline { 1 - 5 } & Mediana & {$[\mathrm{q} 1-\mathrm{q} 3]$} & Mediana & {$[\mathrm{q} 1-\mathrm{q} 3]$} & \\
\hline Idade & 45,5 & {$[25-67]$} & 42 & {$[22-63]$} & 0,024 \\
VHS & 25 & {$[14-57,8]$} & 20 & {$[7-50]$} & $<0,001$ \\
PCR & 10 & {$[4,2-32,7]$} & 15 & {$[5,1-44,4]$} & 0,001 \\
\hline
\end{tabular}

Os resultados do VHS são expressos em mm na primeira hora e da proteína C reativa em mg/L.

\section{Discussão}

Para que um teste seja interpretado e tenha seu valor diagnóstico, são necessários valores de referência que estabelecem um padrão de normalidade e, consequentemente, anormalidade. Por essa razão, os valores de referência para exames laboratoriais são bastante discutidos e frequentemente são revistos e atualizados ${ }^{1819}$.

Visto que os valores de referência são adotados de acordo com a metodologia utilizada e são dependentes de um cálculo que tem como base os valores normais para uma população saudável, cada vez mais a comunidade científica se conscientiza da importância de realizar estudos analisando os resultados das populações locais e seus fatores próprios como idade, gênero, epidemiologia, costumes e assim reavaliar os valores ditos como referência, bem como a aplicabilidade ideal dos testes para cada situação ${ }^{20-22}$. Na contramão desta tendência mundial, o Brasil permanece estagnado em valores e práticas que não necessariamente são os representativos e adequados para uma população tão numerosa e diversificada.

Tendo o valor de 6 a $8 \mathrm{mg} / \mathrm{L}$ considerado um resultado normal por grande parte dos laboratórios que utilizam a mesma metodologia para a determinação da proteína C-reativa, os resultados das amostras gerais analisadas neste estudo mostraram-se elevadas para o método usado. A mesma situação repetiu-se quando as amostras foram separas por sexo, em que tanto as mulheres como os homens mostraram resultados acima dos valores de referência. Entretanto, os homens se destacaram tendo um aumento mais acentuado na determinação da PCR quando comparado às mulheres (Tabela 2).
Para VHS os valores utilizados como referência para o sexo masculino são de até $15 \mathrm{~mm}$ e para o sexo feminino, de até $20 \mathrm{~mm}$. Assim, os valores obtidos nas análises mostraram se superiores aos indicados, quando vistos de forma geral. Analisando quanto ao sexo, ocorreu um resultado contrastante com os encontrados para PCR: ambos os sexos mostram-se acima dos valores de normalidade, porém foram as mulheres que mostraram aumento mais expressivo em comparação aos homens nesse.

Sendo os testes de VHS e PCR relacionados e capazes de refletir um processo inflamatório em curso, é interessante observar a tendência masculina a ter valores elevados detectados pela quantificação da proteína C-reativa, enquanto as mulheres são mais suscetíveis à detecção pelo tempo de hemossedimentação. Estudos anteriores já haviam atestado a eficiência do uso da PCR para detecção de doenças associadas a inflamação tanto em homens ${ }^{23}$, quanto em mulheres ${ }^{24}$. Porém, ainda existem poucos dados referentes à possível sensibilidade que os sexos possam ter na utilização de uma metodologia específica.

Os dados obtidos nesse estudo mostraram que os homens e mulheres analisados para os procedimentos de PCR e VHS obtiveram valores acima da normalidade em ambas as metodologias, corroborando a já bem estabelecida relação entre os testes. Além disso, o estudo também mostrou que os testes tendem a se comportar de forma distinta de acordo com o gênero, com as mulheres tendo maior sensibilidade aparente ao uso da VHS enquanto os homens foram mais sensíveis à PCR. 


\section{Conclusão}

O diagnóstico laboratorial integra o sistema de saúde pública e o aprofundamento de aspectos relacionados às metodologias e atualização dos valores de referência para os exames clínicos é essencial para o desenvolvimento do sistema de saúde como um todo.

Os dados desta pesquisa mostraram o perfil geral de uma população local para os exames de proteína C-reativa e velocidade de hemossedimentação, cujos resultados foram discrepantes dos valores de normalidade utilizados na literatura. Além disso, os valores encontrados também sugerem diferenças na sensibilidade diagnóstica para pacientes do sexo feminino $\mathrm{e}$ masculino, nas metodologias empregadas.

Esses resultados corroboram uma ideia que já é aplicada por diversos países, a qual sugere a revisão das formas de avaliação laboratorial, levando em consideração características regionais e fatores como sexo e idade para atribuir valores de referência e, consequentemente a escolha do método mais adequado de diagnóstico. Sendo o Brasil um país de ampla extensão territorial e variada população, estudos são necessários a fim de que se estabeleça um detalhamento mais aprofundado, considerando dados epidemiológicos e as características regionais da população brasileira para investigar possíveis influências e estratificação de valores nos testes laboratoriais.

\section{Referências}

1. Kumar V. Robbins and Cotran Pathologic Basis of Disease. 9 ed. Elsevier; 2014.

2. Wellen, K. E. \& Hotamisligil, G. S. Inflammation, stress , and diabetes. J Clin Invest 2005;115:1111-1119.

3. Monteiro R, Azevedo I. Chronic inflammation in obesity and the metabolic syndrome. Mediators Inflamm; 2010.

4. Stefanova KI et al. Pathobiochemical Mechanisms Relating Iron Homeostasis to Parameters of Inflammatory Activity and Autoimmune Disorders in Rheumatoid Arthritis. Folia Med. (Plovdiv), 2016;58:257-263.

5. Balkwill, F. \& Mantovani, A. Inflammation and cancer: Back to Virchow? Lancet 357, 539-545;2001.
6. Libby, P. Inflammation and cardiovascular disease mechanisms 1 - 3. Am J Clin Nutr 2006;83:456-460.

7. Disease, C. A. Inflammation, Atherosclerosis, and Coronary Artery Disease. N. Engl. J. Med. 2005;353:429 430.

8. Pincus, T., Gibson, K. A. \& Shmerling, R. H. An evidencebased approach to laboratory tests in usual care of patients with rheumatoid arthritis. Clin. Exp. Rheumatol. 2014;32:S-8.

9. Aguiar, F. J. B. et al. Proteína C reativa: aplicações clínicas e propostas para utilização racional. Rev. Assoc. Med. Bras. 2013;59:85-92.

10. Denardi, Celise AS; Casella Filho, Antonio; Chagas, A. C. A Proteína C-Reativa na Atualidade. Rev SOCERJ 2008;21:329-334.

11. Jou, J. M. et al. ICSH review of the measurement of the erythocyte sedimentation rate. Int. J. Lab. Hematol. 2011;33:125-132

12. Olshaker, J. S. \& Jerrard, D. A. The erythrocyte sedimentation rate. J. Emerg. Med. 15, 869-74;1997.

13. Harrison, M. Erythrocyte sedimentation rate and C-reactive protein Normalisation of an. Aust Presc 2015;3838:93-4.

14. Osei-Bimpong, A., Meek, J. H. \& Lewis, S. M. ESR or CRP? A comparison of their clinical utility. Hematology 2007;12:353-357.

15. Boyd, J. C. Defining laboratory reference values and decision limits: Populations, intervals, and interpretations. Asian J. Androl. 2010;12:83-90.

16. Helmersson-Karlqvist, J., Ridefelt, P., Lind, L. \& Larsson, A. Reference values for 34 frequently used laboratory tests in 80-year-old men and women. Maturitas 2016;92:97101.

17. Ribeiro, A. L. P. et al. Cardiovascular Health in Brazil. Circulation 2016;133:422-433.

18. Geffré, A. et al. Reference values: A review. Vet. Clin. Pathol. 2009;38:288-298.

19. Katayev, A., Balciza, C. \& Seccombe, D. W. Establishing reference intervals for clinical laboratory test results: Is there a better way? Am. J. Clin. Pathol. 2010;133:180-186.

20. Lugada, E. S. et al. Population-based hematologic and immunologic reference values for a healthy Ugandan population. Clin. Diagn. Lab. Immunol. 2004;11:29-34.

21. Hammerlid, E., Adnan, A. \& Silander, E. Populationbased reference values for the European Organization for Research and Treatment of Cancer Head and Neck module. Head Neck 2017;1-12. doi:10.1002/hed.24870

22. Koram, K. et al. Population based reference intervals for common blood haematological and biochemical parameters in the akuapem north district. Ghana Med. J. 2007;41:160-6. 
23. Koenig, W. et al. Predicts Future Risk of Coronary Heart Disease in Initially. 237-243;1999.

24. Ridker PM, Hennekens, CH, Buring JE, Rifai N C.Reactive Protein and Other Markers of Inflammation in the Prediction of Cardiovascular Disease in Women. AORN J. 2001;73:1176.

\section{Como citar este artigo:}

Valadas J, Foigt V, Raupp WA, Freitas TAB, Rotta L. Correlação entre os resultados de proteína c-reativa e velocidade de hemossedimentação. Rev. Aten. Saúde. 2019; 17(60): 05-10. 